\title{
Adsorptive Removal of Disinfection Byproduct (DBP) Precursors by Carbon Nanotubes
}

\author{
Betul Aykut-Senel $^{1}$, Cihan Ozgur ${ }^{2}$, S. Sule Kaplan-Bekaroglu ${ }^{3}$, Nuray Ates ${ }^{4}$ \\ ${ }^{1}$ Department of Environmental Engineering, Suleyman Demirel University, Isparta, Turkey \\ betulaykut32@gmail.com \\ ${ }^{2}$ Sutculer Vocational High School, Isparta University of Applied Science, Isparta, Turkey \\ cihanozgur@isparta.edu.tr \\ ${ }^{3}$ Department of Environmental Engineering, Suleyman Demirel University, Isparta, Turkey \\ sulebekaroglu@sdu.edu.tr \\ ${ }^{4}$ Department of Environmental Engineering, Erciyes University, Kayseri, Turkey \\ nuraya@erciyes.edu.tr
}

\begin{abstract}
Nowadays, researches related to adsorption has shifted to nanostructured materials such as nanotubes. Carbon nanotubes (CNTs) have been widely used in the removal of organic and inorganic many contaminants due to their high porosity, large surface area, hollow structure and strong affinity for pollutants. CNTs are classified into single-walled carbon nanotubes (SWCNT) and multi-walled carbon nanotubes (MWCNT) according to the principle of layers of carbon atoms in the wall of nanotubes. The presence of natural organic matter (NOM) in the water is a major concern because the reaction between chlorine and NOM leads to the formation of hazardous disinfection by-products (DBPs), which pose risks to human health. The main objective of this work was to investigate NOM removal from drinking water using SWCNT (CNT-1) and MWCNT (CNT-2). For the adsorption experiments, water samples were taken from influent of coagulation unit of Konya Drinking Water Treatment Plant (Turkey). Kinetic and isotherm tests were performed with employing the variable-dose completely mixed batch reactor bottle-point method. The NOM removal was characterized by ultraviolet absorbance at $254 \mathrm{~nm}\left(\mathrm{UV}_{254}\right)$ and dissolved organic carbon (DOC). Kinetics data for the removal of NOM were obtained and were best fitted by the pseudo-second-order model. Isotherm experiments were carried out $10-600 \mathrm{mg} / \mathrm{L}$ adsorbent dosages. Maximum DOC removal for CNT-1 and CNT-2 were 32\% and 57\% respectively, after 72 hours of contact time. The highest $\mathrm{UV}_{254}$ removal occurred for CNT-2 was $73 \%$ for 72 hours of contact time. Isotherm experiment results were fitted well with a modified Freundlich isotherm model $\left(\mathrm{R}^{2}\right.$ value of 0.99$)$. Freundlich capacity parameters $\left(\mathrm{K}_{\mathrm{F}}\right)$ were 0.32 and $1.95\left(\mathrm{mg}\right.$ DOC/g carbon) ${ }^{1-\mathrm{n}}$ and Freundlich logarithmic term (n) values for CNT-1 and CNT-2 calculated as 0.93 and 1.58, respectively.
\end{abstract}

Keywords: Adsorption, Carbon nanotubes, Drinking water, Natural Organic Matter, Ultraviolet absorbance, Water treatment.

\section{Introduction}

Natural organic matter (NOM) is a heterogeneous mixture of humic substances, hydrophilic acids, proteins, lipids, carbohydrates, carboxylic acids, amino acids and hydrocarbons [1,2]. NOM many cause problems with indirect health impacts in drinking water treatment plants and water distribution systems as well as operational and aesthetic issues. Some of NOM-caused issues are i) increased coagulant dose; 2) shorter filter run times 3) membrane fouling 4) regulated and nonregulated disinfection by-products (DBPs) formation 5) bacterial growth and biofilm formation in drinking water distribution systems 6) carrier for hydrophobic organic (pesticides) and metals [3,4]. Accordingly, several processes have been employed to remove NOM from water, including coagulation, membrane filtration, ion exchange, advanced oxidation processes, and adsorption technology (technology (e.g. powdered activated carbon and granular activated carbon) [5]. Among them, adsorption is considered as one of the most effective methods [2,6]. Although activated carbon is the most widely used adsorbent in the adsorption process, recently carbon nanotubes (CNTs) have been gradually applied to the removal of organic contaminants from water through adsorption processes. [3, 6]. CNTs, with their high surface areas, hydrophobicity, porosity, and rapid sorption kinetics, have been exploring as one of the next-generation adsorbents [7]. The comparisons of CNTs with other adsorbents made by the foregoing researchers suggest that CNTs are promising adsorbents for water treatment applications. CNTs are classified two main species; single-walled nanotubes (SWNTs) and multi-walled nanotubes 
(MWNTs) [8]. The CNTs have nanometer-sized diameters SWCNTs $<2 \mathrm{~nm}$ and $2<$ MWCNTs $<100 \mathrm{~nm}[9,10]$. The main purpose of this study was to investigate the effectiveness of SWCNTs and MWCNTs in removing NOM from drinking water.

\section{Materials and Method}

Water samples were taken from the influent of the coagulation unit in Konya Drinking Water Treatment Plant. Original SWCNTs and MWCNTs used in adsorption tests were supplied commercially (Sigma Aldrich). Adsorption isotherm experiments were carried out using the bottle-point method in completely mixed batch reactors (CMBR) by applying different doses. The NOM removal was characterized by ultraviolet absorbance at $254 \mathrm{~nm}\left(\mathrm{UV}_{254}\right)$ and total organic carbon (DOC). For CMBR kinetic experiments, fixed adsorbent doses of $300 \mathrm{mg} / \mathrm{L}$ were tested for 2, 4, 8, 12, 24, 36, 48, 72, and 96 hours. All isotherm experiments were carried out based on determined contact time to reach equilibrium condition from the kinetic tests for the adsorbent doses of $10 \mathrm{mg} / \mathrm{L}-600 \mathrm{mg} / \mathrm{L}$ at a mixing speed of 100 rpm. In order to evaluate NOM removal performance of CNTs, supernatant was analyzed for DOC and UV 254 absorbance. UV absorbance values were measured at $254 \mathrm{~nm}$ using a UV-visible spectrophotometer (UV1700, Shimadzu). DOC content was determined in the TOC-L CPH (Shimadzu) instrument according to the high temperature combustion method (Standard Method 5310B).

\section{Results/Discussion}

This study evaluates NOM removal from effluent of coagulation process using CNT-1 (SWCNT) and CNT-2 (MWCNT) in drinking water treatment plant receiving from a dam. In the study, kinetic tests were performed at a dose of $300 \mathrm{mg} / \mathrm{L}$ carbon nanotube in 9 different contact times. As a result of the kinetic experiments, the contact time required for reaching equilibrium was observed as 72 hours. Kinetics data for the removal of NOM were best fitted by the pseudosecond-order model. Figure 1 shows the $\mathrm{UV}_{254}$ absorbance removal of the adsorbents after 72 hours of contact time under isotherm test conditions. In general, as the adsorbent dose for CNT-2 was increased, the removal efficiency of $\mathrm{UV}_{254}$ absorbents increased. The highest removal efficiency for CNT-2 was $73 \%$ at $500 \mathrm{mg} / \mathrm{L}$. In Figure 1, it is seen that the $\mathrm{UV}_{254}$ removal efficiency of multi-walled carbon nanotubes is higher than that of single-walled carbon nanotubes.

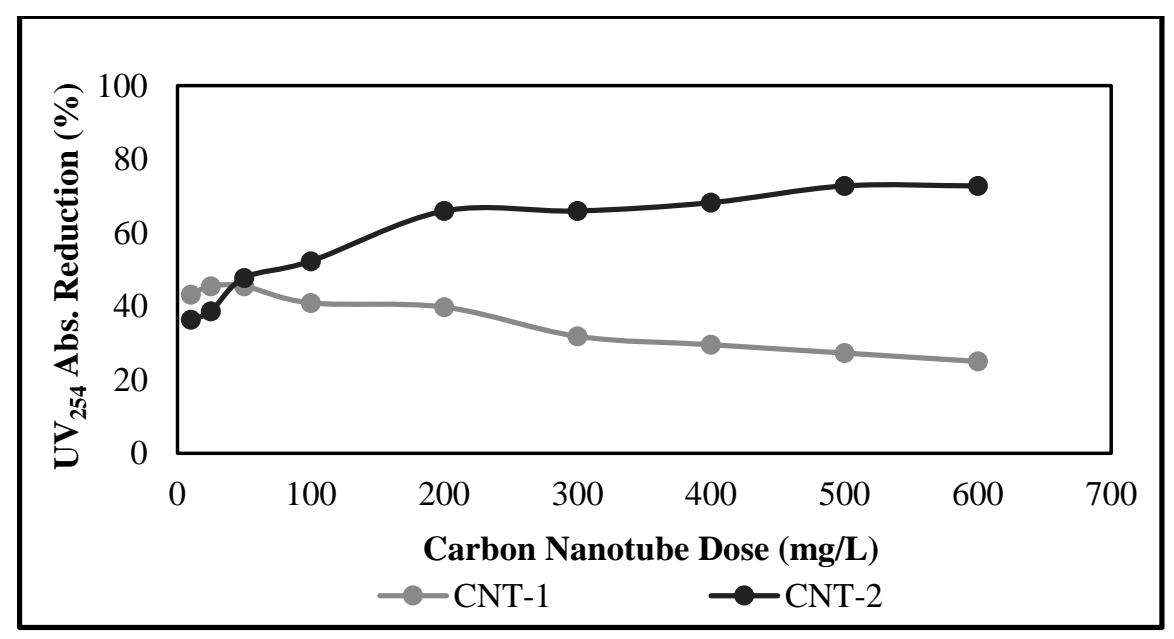

Fig. 1: $\mathrm{UV}_{254}$ absorbance reductions (\%) obtained by CNT-1 and CNT-2

Figure 2 shows the DOC removal for CNT-1 and CNT-2 at different adsorbent doses for 72 hours of contact time. Similar to $\mathrm{UV}_{254}$ removal efficiency, CNT-2 has higher DOC removal efficiency than CNT-1. The highest DOC removal for CNT-2 it is $57 \%$ at $400 \mathrm{mg} / \mathrm{L}$. Modified Freundlich isotherm was applied for adsorption isotherm modelling. 
Considering the determination coefficients $\left(\mathrm{R}^{2}\right.$ value 0.99$)$, the concordance of the NOM adsorption equilibrium data with the Freundlich isotherm model was quite high. In addition, the correlation between the calculated $\mathrm{q}_{\mathrm{e}}$ values and experimental $\mathrm{q}_{\mathrm{e}}$ experiments is quite high. Freundlich isotherm parameters for NOM adsorption of CNTs are given in Table 1.

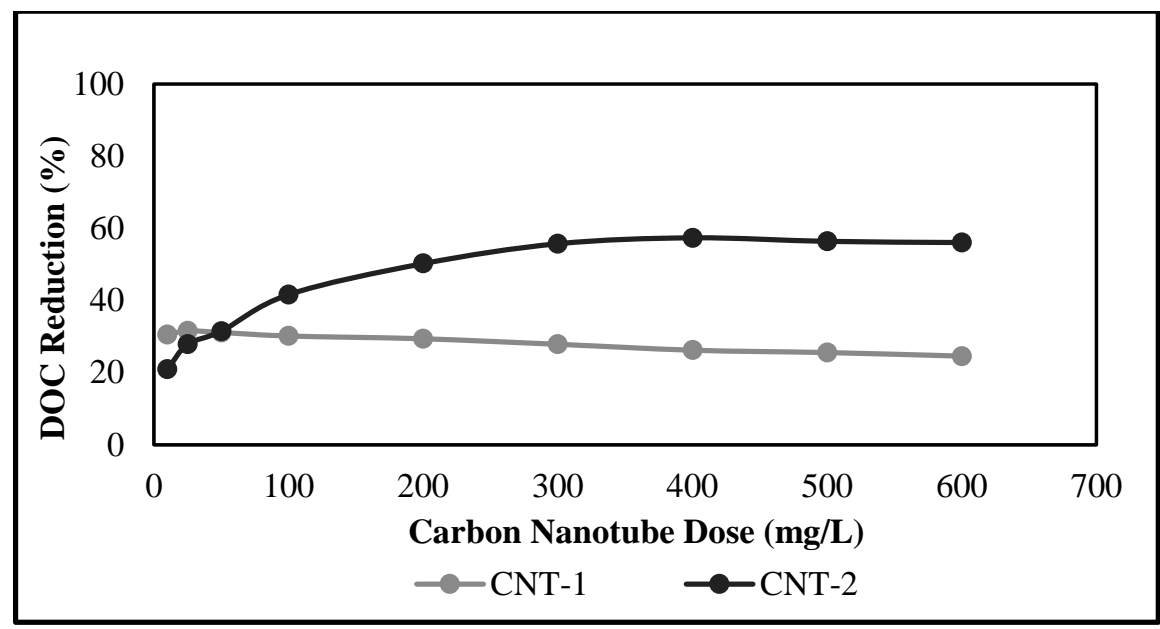

Fig. 2: DOC reductions (\%) obtained by CNT-1 and CNT-2.

Table 1: Freundlich isotherm parameters for NOM adsorption of adsorbents.

\begin{tabular}{|l|c|c|c|c|}
\hline Adsorbents & $\mathbf{q}$ & $\mathbf{K}_{\mathbf{F}}$ & $\mathbf{n}$ & $\mathbf{R}^{\mathbf{2}}$ \\
\hline CNT-1 & $1.25-93.23$ & 0.32 & 0.93 & 0.99 \\
\hline CNT-2 & $2.85-63.80$ & 1.95 & 1.58 & 0.99 \\
\hline
\end{tabular}

${ }^{*} \mathrm{~K}_{\mathrm{F}}$ : Freundlich capacity parameter (mg DOC/g carbon) $)^{1-\mathrm{n}} ; \mathrm{n}$ : Freundlich logarithmic term $\mathrm{q}_{\mathrm{e}}$ : adsorption capacity $(\mathrm{mg} / \mathrm{g}) ; \mathrm{R}^{2}$ : Determination coefficient.

Joseph et al. [3] studied the NOM removal of water containing low DOC and carbon materials such as single-walled CNT, multi-walled CNT and PAC in the natural water source with Freundlich isotherm. Joseph et al. [3] reported that the isotherm parameters $\mathrm{K}_{\mathrm{F}}$ and $\mathrm{n}$ values for SWCNT were in the range of 2.28-2.82 and 0.486-0.644 in the adsorption experiments in different water sources, respectively. On the other hand, $\mathrm{K}_{\mathrm{F}}$ values were varied from 1.080 to 2.663 and $\mathrm{n}$ values were ranged from 0.185 to 0.750 for MWCNT. In the results of the study performed by $\mathrm{Su}$ and $\mathrm{Lu}$ [7], the values of $\mathrm{n}, \mathrm{K}_{\mathrm{F}}$ and $\mathrm{R}^{2}$ were calculated as $1.51,7.84$ and 0.94 , respectively for Freundlich model at $25{ }^{\circ} \mathrm{C}$ temperature. Shimuzi et al. [2] showed compatibility with the Freundlich model of different types of NOM adsorption with MWCNT in water resources, $\mathrm{K}_{\mathrm{F}}, \mathrm{n}$ and $\mathrm{R}^{2}$ values were calculated as $1.13,0.38$, and 0.99 , respectively.

\section{Conclusion}

In recent years, carbon nanotubes have become promising adsorbents for water treatment especially, in removing organic and inorganic contaminants. This study focused on removal of NOM using CNTs. The highest NOM and UV $\mathrm{U}_{254}$ removal was obtained after adsorption with multi-walled carbon nanotube. This results are very important in the type of adsorbent to be chosen in NOM removal. Study results showed that carbon nanotubes can be a promising adsorbent in NOM removal. Carbon nanotubes can also be effective in controlling the formation of disinfection by-products during drinking water treatment, as they preferentially remove large amounts of UV-absorbing NOM fractions. Nowadays, activated carbon is a widely used adsorbent in water treatment plants due to its low cost and easy applicability. However, as production costs begin to decrease 
and research / applications on NOM removal increase, carbon nanotubes become competitive with activated carbons. Carbon nanotubes are preferred as new generation adsorbents thanks to their high surface area, hydrophobicity, porosity, fast adsorption kinetics and simple regeneration techniques. Recent studies in the literature have been investigating the removal of pollutants as a result of treatment carbon nanotubes with various modification methods. Modification methods may be used in further studies to increase the adsorption capacity of selected carbon nanotubes in this study.

\section{Acknowledgements}

The authors would like to thank the financial support from the Scientific and Technological Research Council of Turkey (TUBITAK) 1001 Research Projects Funding Program with project number 118 Y402.

\section{References}

[1] S. Zhang, T. Shao, T. Karanfil, "The effects of dissolved natural organic matter on the adsorption of synthetic organic chemicals by activated carbons and carbon nanotubes," Water Res., vol. 45, pp. 1378-1386, 2011.

[2] Y. Shimizu, M. Ateia, C. Yoshimura, "Natural organic matter undergoes different molecular sieving by adsorption on activated carbon and carbon nanotubes," Chemosphere., vol. 203, pp. 345-352, 2018.

[3] L. Joseph, "Removal of natural organic matter from potential drinking water sources by combined coagulation and adsorption using carbon nanomaterials," Sep. Purif. Technol., vol. 95, pp. 64-72, 2012.

[4] H. Humbert, "Natural organic matter (NOM) and pesticides removal using a combination of ion exchange resin and powdered activated carbon (PAC)," Water Res., vol. 42, pp. 1635-1643, 2008.

[5] M. Ateia, O. G. Apul, Y. Shimizu, A. Muflihah, C. Yoshimura, T. Karanfil, "Elucidating Adsorptive Fractions of Natural Organic Matter on Carbon Nanotubes,” Environ. Sci. Technol., vol. 51, pp. 7101-7110, 2017.

[6] A. Bhatnagar, M. Sillanpaa, "Removal of natural organic matter (NOM) and its constituents from water by adsorptionA review," Chemosphere., vol.166, pp. 497-510, 2017.

[7] C. Lu, F. Su, "Adsorption of natural organic matter by carbon nanotubes," Sep. Purif. Technol., vol. 58, pp. 113-121, 2007.

[8] H. Hyung, J. Fortne, J. B. Hughes, J. H. Kim, "Natural Organic Matter Stabilizes Carbon Nanotubes I the Aqueous Phase," Environ. Sci. Technol., vol. 41, pp. 179-184, 2007.

[9] B. Sarkar, S. Mandal, Y. F. Tsang, P. Kumar, K. H. Kim, Y.S. Ok, "Designer carbon nanotubes for contaminant removal in water and wastewater: a critical review", Sci. Total Environ., vol. 612, pp. 561-581, 2018.

[10] Z. Fallah, E. N. Zare, M. Ghomi, F. Ahmadijokani, M. Amini, M. Tajbakhsh, M. Arjmand, G. Sharma, H. Ali, A. Ahmad, P. Makvandi, E. Lichtfouse, M. Sillanpaa, R. S. Varma, "Toxicity and remediation of pharmaceuticals and pesticides using metal oxides and carbon nanomaterials”, Chemosphere., vol. 275, pp. 130055, 2021. 